\title{
Prosthodontic Rehabilitation of $A$ Patient With Combination Syndrome
}

\author{
Shanthi Priya $\mathrm{K}^{1}$, Reddi Narasimha Rao $\mathrm{M}^{2}$, Raja Reddy $\mathrm{N}^{3}$, Sunil $\mathrm{M}^{4}$
}

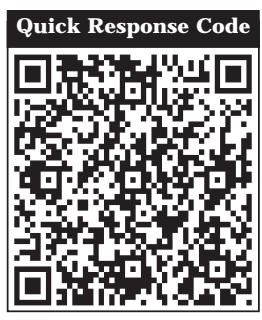

doi : $10.5866 / 2015.7 .10058$

1Post Graduate Student

${ }^{2 \& 3}$ Reader

${ }^{4}$ Professor

C.K.S Theja Institute of Dental Sciences and Research Tirupathi, Andhra Pradesh

\section{Article Info:}

Received: J anuary 8, 2015

Review Completed: February 7, 2015

Accepted: March 10, 2015

Available Online: April, 2015 (www.nacd.in)

(c) NAD, 2015 - All rights reserved

Email for correspondence:

kota.shanthi@gmail.com

\begin{abstract}
:
Combination syndrome is a dental condition that is commonly seen with a completely edentulous maxilla and partially edentulous mandible with preserved anterior teeth. This syndrome consists of severe anterior maxillary resorption combined with hypertrophic and atrophic changes in different quadrants of maxilla and mandible. Combination syndrome makes it a challenging condition in dentistry which requires significant experience along with advanced restorative and surgical skills. Difficulty in chewing and mastication is of special concern in such a patient. Though removable partial denture could be the choice of treatment; precision attachment can definitely deliver better satisfaction to the patient if proper technique is followed and this form of treatment is considered as one of the most sophisticated treatment. The present article provides an overview and a simplified approach to this treatment modality by a clinical case report.
\end{abstract}

Key words: Combination syndrome, Complete Denture, Attachment, Removable Partial Denture.

\section{INTRODUCTION:}

Our ever-increasing knowledge of the oral environment, together with technological improvements and good armamentarium, has taken us to give a restoration which is esthetically pleasing and comfortable. Rehabilitation of Kennedys class I and class II cases can be challenging where a fixed prostheses cannot be fabricated and implant retained restoration sometimes not possible due to insufficient amount of bone or economic reasons. ${ }^{1}$ Precision attachments could be extracoronal and intracoronal. Intracoronal describes an attachment within the confines of the cusps and normal proximal axial contour or within the normal contours of the crown of a tooth. ${ }^{2}$ The extracoronal attachment projects outsidethe crown and provides either a rigid or resilient connection between the teeth and the prosthesis. Precision attachment has long been considered the highest form of partial denture therapy. Attachment retained RPD is the treatment modality that can facilitate both esthetic and a functional replacement of missing teethand oral structures. ${ }^{3,4}$ This article outlines some of the essential considerations in planning a treatment for a typical combination syndrome case.

\section{CASE REPORT:}

A 55 year old female reported to Department of prosthodontics, C.K.S Theja institute of dental sciences and research, Tirupathi, with a chief complaint of missing teeth in upper arch and in right

\section{Indian Journal of Dental AdVAncements}

Journal homepage: www. nacd. in 
and left lower posterior region of the jaw and inability to eat food. She was wearing maxillary complete denture and mandibular distal extension RPD which was compromised both functionally and esthetically. Patient's medical history was evaluated and found to be non contributory. On intra oral examination there was mobile flabby tissue in the anterior maxilla from right canine region to left canine region and 17 to 27, 37, 36, 34, 45, 46, 47 teeth were missing and there was supra-eruption of existing teeth (Figure 1). Analyzing the patient's existing clinical condition of compromised esthetics, impaired function with the existing dentures, it was planned to construct maxillary complete denture and mandibular removable partial denture with extracoronal attachment. The patient rejected the options of implants because of the need for additional surgery and the unacceptable duration of treatment phase.

\section{TECHNIQUE :}

- Diagnostic impressions were made and a tentative jaw relation was recorded and mounting was done on a three point articulator to access the available space for planning an attachment retained mandibular partial denture.

- Maxillary preliminary impression was made with impression compound, special tray was fabricated with autopolymerizing acrylic resin, border moulding was done using low fusing compound and final impression was made by providing relief (Figure 2) over the flabby tissue in the maxillary anterior region using light body elastomer and poured with Type III dental stone.

- Wax pattern was fabricated on the refractory cast which was duplicated from the master cast for the fabrication of metal denture base. Following casting and finishing, metal base was incorporated in to autopolymerizing acrylic denture base over which occlusal rims were fabricated.

- Tooth preparation was done after Root canal treatment on 35,33,43,44 to receive PF M crowns (Figure 3). I mpression was made and poured in die stone following which crowns have been waxed to full contour and milled in wax for maximum guiding plane surface.
- The male component was attached to the axial surfaces of the abutments bilaterally on both the arches in relation to 35 and 44 using a dental surveyor, (Figure 4) investing and casting was done. Metal try-in of the copings was done to evaluate the fit of the casting. Ceramic layering was done on the metal frame work and tried. The fabricated metal ceramic crowns were provisionally cemented (Figure 5) with the attached male components and pick up impression is made using putty, light body (Aquasil, Densply) to fabricate the removable partial denture with bilateral precision attachments.

- Cast was poured from the impression and removable frame work with female component was fabricated over the cast. The removable framework is tried in the patient's mouth with the incorporated female component (Metal housing with black rubber spacer) and evaluated for passive fit over the o-ring (male component). Occlusal rims were fabricated on the framework of the mandibular removable partial denture.

- Maxillomandibular relations were recorded. Teeth arrangement and try in was donefollowed by acrylization by incorporating nylon cap along with housing in the RPD. (Figure:6)The fixed partial denture was cemented with glass ionomer cement and the removable partial denture with bilateral precision attachment and maxillary complete denture was inserted. The method of placing and removal of dentures was instructed to the patient. Post insertion checkup was done for 1 to 2 week interval (Figure 7).

\section{DISCUSSION}

Different treatment approaches have been suggested for patients with an edentulous maxilla and some remaining anterior mandibular teeth. The choice of treatment ultimately depends on the patien's oral condition, economic status and desire for fixed or removable prosthesis. Dr. Herman Chayes first reported the invention of attachment in early 20 th century. ${ }^{5}$ To the late 20 th century, with growing technology the attachment has been applied to the superstructure of implant. Precision attachment has exceptional feature of being a removable prosthesis with improved aesthetics, less post-operative adjustments and better patient comfort. ${ }^{6}$ They are mostly indicated in long 


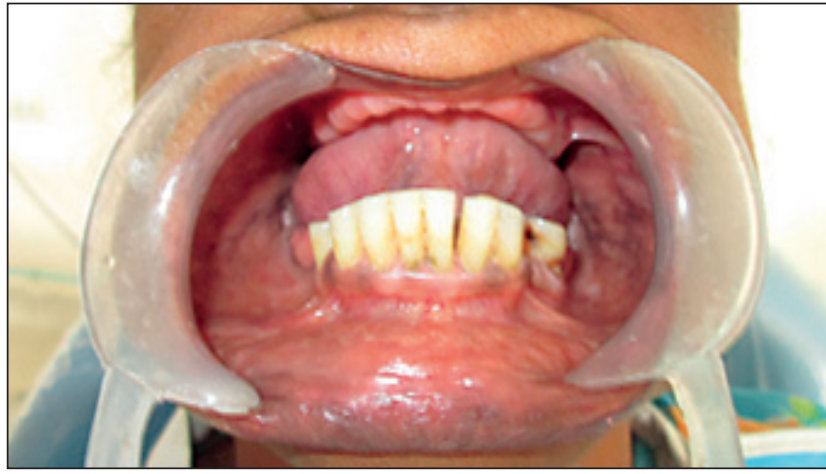

Figure 1: Preoperative Intraoral view showing completely edentulous maxilla and partially edentulous mandible.

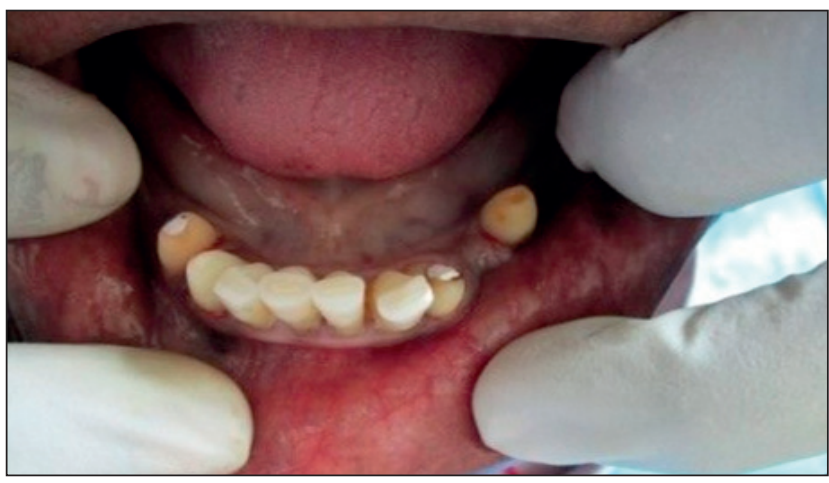

Figure 3: Tooth Preparation done in 35, 33, 43, 44 teeth.

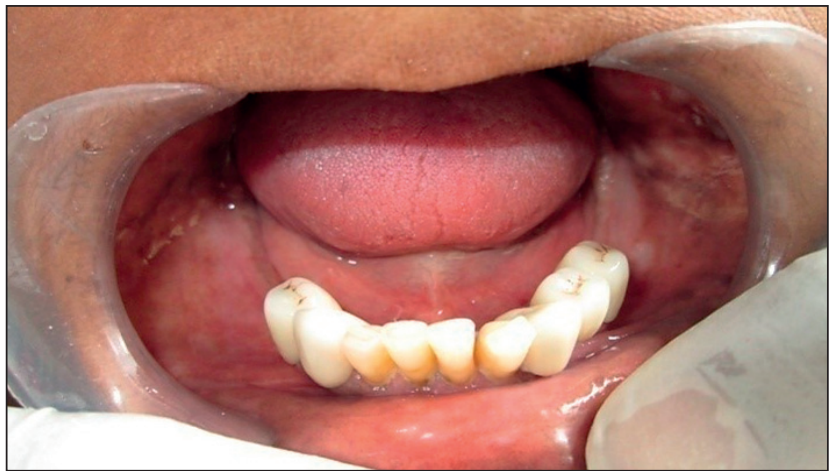

Figure 5: Cemented PFM crowns for 35, 34, 33, 43, 44 teeth.

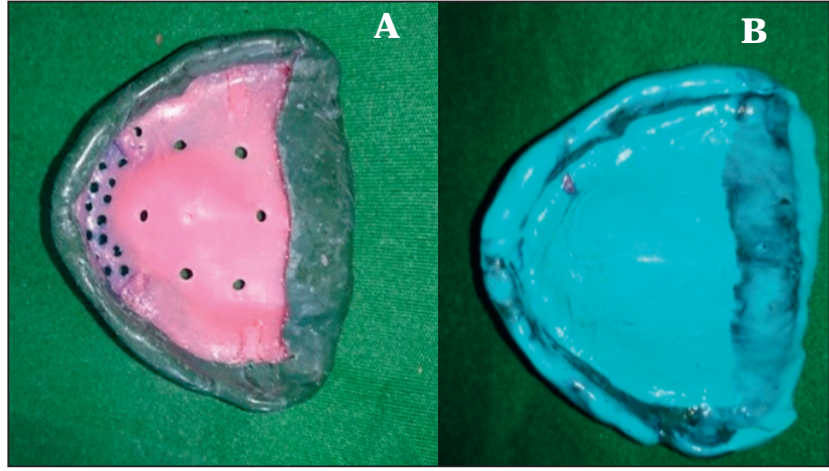

Figure 2: (A) Relief provided in the maxillary special tray for the flabby tissue, (B) Final impression made using light body elastomer

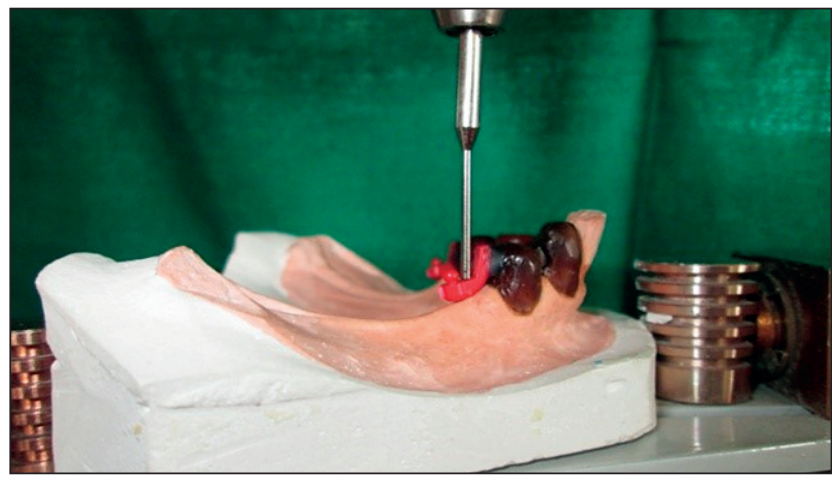

Figure 4: Male component attached to the abutment and checked with Surveyor.

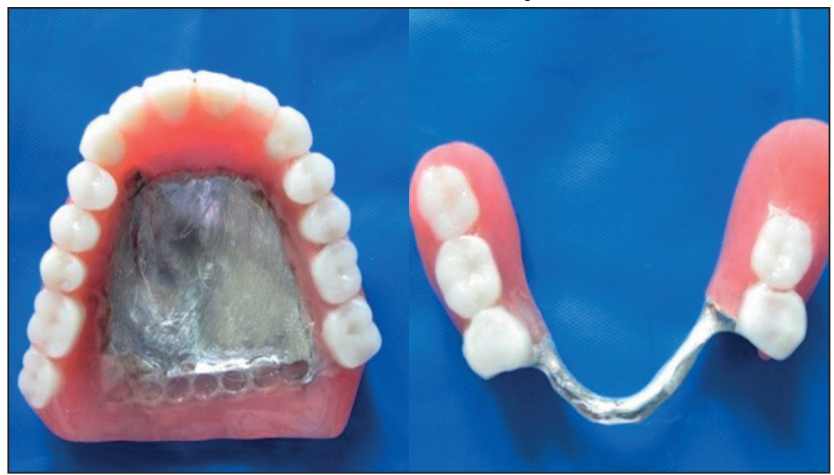

Figure 6: (A) Processed Maxillary metal denture, (B) Processed Mandibular removable partial denture with attachment

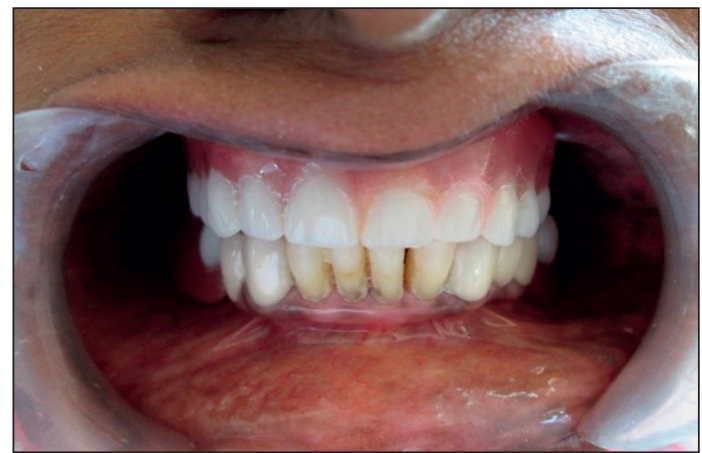

Figure 7: Postoperative Intraoral View with inserted dentures. 
edentulous spans, distal extension bases and non parallel abutments. Understanding the difference in nature and behavior of the tissues supporting RPD is critical for long term success of the prosthesis. ${ }^{7}$ These differences multiplied by the function create major stresses on the tooth-tissue prosthesis. ${ }^{5}$ The stress-control on abutment is an essential factor for the success of distal extension cast partial denture which is achieved through broad coverage and stable denture base, rigid design, splinting of abutments, proper selection of attachment and clasp design.8,9

In the present case report maxillary denture was reinforced with metal denture base and the abutments were of adequate clinical crown height to receive attachment; multiple abutments were splinted anterior to edentulous span to aid in better distribution of stresses. Kapur et al have suggested that splinted 1st and 2nd premolar by full coverage crown, has provided good support and improved the prognosis of cast partial denture. ${ }^{10}$ With its elasticity it is possible to control the flexure and construct a resilient and shock absorbing prostheses.

\section{CONCLUSION}

Removable partial dentures fabricated with precision attachments are the viable options for patients in whom fixed prosthesis and implants are contraindicated. Adherence to precision techniques, proper diagnosis and periodic recall will result in successful treatment by preserving of the patient's existing dentition.

\section{REFERENCES}

1. Makkar S, Chabbra A, Khare A. Attachment Retained Removable Partial Denture: A CaseReport. IJ CDS 2011; 2(2):39-43.

2. Elliot Feinberg, Edward M. Feinberg, et al .Attachment Retained Partial Denture. Nys Dent J 1984:161-164.

3. Burns DR, Ward J E. A review of attachments for removable partial denture design: part 1. Classification and selection. Int J Prosthodont 1990; 3:98-102.

4. Burns DR, Ward J E. A review of attachments for removable partial denture design: part 2. Treatment planning and attachment selection. Int J Prosthodont 1990; 3:169-174.

5. Preiskel HW. Precision Attachments in Prosthodontics: Overdentures and Tel escopic Prostheses. Volume 2. Chicago, II: Quintessence Publishing Co, Ltd; 1985.

6. Feinberg E. Diagnosing and prescribing therapeutic attachment-retained partial dentures. NYS Dent J 1982; 48(1):27-29.

7. Gillings BRD. Magnetic retention for complete and partial dentures Part 1. J Prosthet Dent 1981; 45:484.

8. Preiskel H. Precision attachments for free-end saddle prostheses. Br Dent J 1969; 127:462-468.

9. Picton DC, Willis DJ. Viscoelastic properties of the periodontal memebrane and mucous membrane. J Prosthet Dent 1978; 40:263-272.

10. Kapur KK, Deupree R, Dent RJ , Hasse AL. A randomized clinical trail of two basic removable partial denture designs. Part-I: Comparsion of fiveyear success rates and periodontal health. J Prosthet Dent 1994; 72(3):268-282.

\section{Gain quick access to our journal online View our journal at} wWW.nacd.in 